\title{
Susac syndrome
}

INSERM

\section{Source}

INSERM. (1999). Orphanet: an online rare disease and orphan drug data base. Susac syndrome. ORPHA:838

Susac syndrome (SS) is a rare disorder characterized by the triad of central nervous system (CNS) dysfunction, branch retinal artery occlusions (BRAOs) and sensorineural hearing loss (SNHL). It is presumably due to autoimmune-mediated occlusions of microvessels in the CNS, the retina, and the inner ear. 